\title{
Microstructure and Mechanical Properties of MWCNTs Reinforced A356 Aluminum Alloys Cast Nanocomposites Fabricated by Using a Combination of Rheocasting and Squeeze Casting Techniques
}

\author{
Abou Bakr Elshalakany, ${ }^{1,2}$ T. A. Osman, ${ }^{2}$ A. Khattab, ${ }^{2}$ B. Azzam, ${ }^{2}$ and M. Zaki' \\ ${ }^{1}$ Production Engineering and Printing Technology Department, Akhbar El Yom Academy, Giza, Egypt \\ ${ }^{2}$ Mechanical Design and Production Engineering Department, Cairo University, Giza, Egypt
}

Correspondence should be addressed to Abou Bakr Elshalakany; eng_bakr2011@yahoo.com

Received 4 November 2013; Revised 19 January 2014; Accepted 23 January 2014; Published 1 April 2014

Academic Editor: Sheng-Rui Jian

Copyright (C) 2014 Abou Bakr Elshalakany et al. This is an open access article distributed under the Creative Commons Attribution License, which permits unrestricted use, distribution, and reproduction in any medium, provided the original work is properly cited.

\begin{abstract}
A356 hypoeutectic aluminum-silicon alloys matrix composites reinforced by different contents of multiwalled carbon nanotubes (MWCNTs) were fabricated using a combination of rheocasting and squeeze casting techniques. A novel approach by adding MWCNTs into A356 aluminum alloy matrix with CNTs has been performed. This method is significant in debundling and preventing flotation of the CNTs within the molten alloy. The microstructures of nanocomposites and the interface between the aluminum alloy matrix and the MWCNTs were examined by using an optical microscopy (OM) and scanning electron microscopy (SEM) equipped with an energy dispersive X-ray analysis (EDX). This method remarkably facilitated a uniform dispersion of nanotubes within A356 aluminum alloy matrix as well as a refinement of grain size. In addition, the effects of weight fraction $(0.5,1.0,1.5,2.0$, and $2.5 \mathrm{wt} \%)$ of the CNT-blended matrix on mechanical properties were evaluated. The results have indicated that a significant improvement in ultimate tensile strength and elongation percentage of nanocomposite occurred at the optimal amount of $1.5 \mathrm{wt} \%$ MWCNTs which represents an increase in their values by a ratio of about $50 \%$ and $280 \%$, respectively, compared to their corresponding values of monolithic alloy. Hardness of the samples was also significantly increased by the addition of CNTs.
\end{abstract}

\section{Introduction}

A356 aluminum alloy is a casting alloy consisting of aluminum, silicon, and magnesium. It has good strength and ductility as well as excellent casting characteristics, high corrosion resistance, and good fluidity. The alloy has been widely applied in the machinery, aircraft and defense industries, and particularly in the automotive industry to replace steel components [1, 2]. A356 aluminum alloy has also been used as the basis for obtaining composites with ceramic reinforced particles and fibres such as $\mathrm{SiC}$ and $\mathrm{Al}_{2} \mathrm{O}_{3}$ [3-6]. Incorporation of MWCNTs in aluminium alloy matrix can lead to the production of low cost aluminium composites with improved hardness and strength. These composites can find applications in automotive components like pistons, cylinder liners, and connecting rods.
Traditionally, two approaches have been utilized to apply reinforcement phases to metal matrices: casting methods and powder metallurgy. Stir casting offers a simpler and less expensive alternative, which has been applied commercially in the production of particle reinforcing metal matrix composites. Although stir casting is a reasonable alternative, it has never been used for dispersing MWCNTs to metal matrix composites. This is in part because MWCNTs are lighter than all commercial metals and not wetted by their melts. Furthermore, it tends to entangle with each other and thus to float around and agglomerate on a melt surface if added to metal melt according to their density relative to liquid metal [7].

Carbon nanotubes (CNTs) were discovered by Iijima [8] in 1991. Experiments have shown that CNTs have superior 
TABLE 1: Chemical composition (wt\%) of A356 aluminum alloy.

\begin{tabular}{lccccccr}
\hline Element & $\mathrm{Si}$ & $\mathrm{Mg}$ & $\mathrm{Fe}$ & $\mathrm{Cu}$ & $\mathrm{Zn}$ & $\mathrm{Pb}$ & $\mathrm{Al}$ \\
\hline Percentage & 6.6 & 0.30 & 0.27 & 0.020 & 0.01 & 0.022 & $\mathrm{Bal}$. \\
\hline
\end{tabular}

mechanical properties over carbon fibers, for example, stiffness values up to $1000 \mathrm{GPa}$, an elastic modulus of CNTs as high as $1 \mathrm{TPa}$, strength on the order of $100 \mathrm{GPa}[9,10]$, and thermal conductivity of up to $6000 \mathrm{~W} \mathrm{~m}^{-1} \mathrm{~K}^{-1}$. Since the discovery of CNTs, many interesting studies on composites with CNTs have been performed. One of the remaining challenges is to obtain a homogeneous dispersion of CNTs in matrices; little progress has been made with metal matrix composites reinforced by MWCNTs.

Li et al. [11] successfully dispersed MWCNTs on Mg alloy chips, and then the chips are added to the melt with vigorous stirring. They found a significant improvement up to $36 \%$ in compressive yield strength and ultimate compressive strength only by addition of $0.1 \mathrm{wt} \%$ MWCNTs.

Abbasipour et al. [12] produced 356 aluminium alloys reinforced with CNTs by stir casting and compocasting routes. In order to alleviate problems associated with poor wettability, agglomeration, and gravity segregation, CNTs were introduced into the melts by injection of CNTs deposited aluminum particles instead of raw CNTs. Aluminum particles with a mean diameter of $100 \mu \mathrm{m}$ were first deposited by CNTs using Ni-P electroless plating technique and then injected into the melt agitated by a mechanical stirrer. The slurry was subsequently cast at a temperature corresponding to full liquid as 0.15 and 0.30 solid fractions. The results show that the addition of CNTs to A356 matrix can significantly refine both full liquid and semisolid cast microstructures. Hardness of the samples is significantly increased by the addition of CNTs and A356-CNT composite cast at 0.3 solid fractions.

Zeng et al. [13] developed a new approach by adding MWCNTs into a magnesium-aluminum alloy matrix. In this study, MWCNTs are added into molten alloys in the form of blocks consisting of the mixture of MWCNT and metal powders. The powder is mixed using the ball milling process to obtain a mixture with final compositions to achieve welldispersed MWCNTs. The optical microscopy and scanning electron microscopy revealed a uniform dispersion of CNTs within the magnesium alloy melt without evidence for any reaction between the CNTs and the metallic matrix. They observed a maximum tensile strength at $210.3 \mathrm{MPa}$ and an elongation rate of $8.56 \%$, which represents an increase of $30.8 \%$ and $124.1 \%$, respectively. Therefore, in this study, a novel process was developed to produce metal matrix composites reinforced with MWCNTs. The process can homogenously disperse MWCNTs into an aluminum alloy melt with the help of a moderate stir. In order to decrease the porosity in the composite material, the pressure casting such as die and squeeze casting methods is applied [14]. The application of squeezing pressure during solidification reduces greatly the porosity that may develop from the rheocasting step. The microstructure of nanocomposites and the interface between A356 aluminum-silicon alloy matrix and carbon nanotubes were investigated. In addition, due to the influences of the MWCNTs content on mechanical properties of A356/MWCNT at room temperatures, nanocomposites were fabricated using a combination of rheocasting and squeeze casting techniques which combines the infiltration, mechanical stirring, and the pressure casting such as die and squeeze casting methods effecting as well as its strengthening mechanism were discussed.

\section{Experimental Procedures}

2.1. Syntheses of Carbon Nanotubes and Preparation of Al/MWCNT Metal Blocks Reinforcement. Carbon nanotubes (CNTs) were synthesized by electric arc discharge. The arc is generated between two electrodes (size $\varnothing 6 \times 100 \mathrm{~mm}$ ) using distilled water. The cathode and the anode materials were graphite (99.9\% pure) and were performed under AC arc discharge, $75 \mathrm{~A}$ and $238 \mathrm{~V}$. The size and morphology of carbon nanotube were characterized with high resolution transmission electron microscopy with an accelerating voltage of $200 \mathrm{kV}$. Powder X-ray diffractometer using $\mathrm{Cu}$ Ka radiation $(k=1.54056 \AA, 40 \mathrm{kV}, 30 \mathrm{~mA})$ was used to identify the characterization and the phase of carbon nanotube. MWCNTs were added into molten alloys in the form of blocks ( $\varnothing 20 \mathrm{~mm} \times 30 \mathrm{~mm}$ ) consisting of the mixture of MWCNT and pure aluminum powder. The blocks were cut into small cylindrical solid billets (Ø $20 \mathrm{~mm} \times 5 \mathrm{~mm}$ ). Pure aluminum powder and MWCNTs were of weight ratio of $6: 1$ as shown in Figures 1(a) and 1(b). The blocks were prepared by compressing a mixture of MWCNTs, $\mathrm{Al}$, and stearic acids in a steel mould preheated at $8^{\circ} \mathrm{C}$ with a $70 \mathrm{MPa}$ pressure and compaction time 15 minutes. The starting materials for preparing the MWCNT blocks were MWCNT powders (90\% in purity, $10 \mathrm{~nm}$ in diameter, and $10 \mu \mathrm{m}$ in length), as shown in Figure 6, aluminum powders ( $99.99 \%$, average particle size of $80-100 \mu \mathrm{m}$ ), and stearic acid (chemical purity, $75^{\circ} \mathrm{C}$ melting point). Al powder was mainly used to assist the dispersion of MWCNTs and increase density of MWCNT blocks. Stearic acids were used as adhesive agents. The ball milling process was performed in a rotary ball mill using stainless steel balls with the ball to powder volume ratio of $8: 1$. The mixture was ball milled at $200 \mathrm{rpm}$ for $8 \mathrm{hr}$.

2.2. Melting of A356 Aluminum Silicon Alloy. Hypoeutectic A356 aluminum silicon alloy was used as the experimental alloy, whose chemical compositions are shown in Table 1. The presence of $\mathrm{Mg}$ improves the wettability of the reinforcement by the matrix [15].

Figure 2 schematically shows the experimental setup used in production of the composites. Fabrication of the nanocomposite alloy was carried out according to the following procedures. About $350 \mathrm{~g}$ of the A356 Al alloy was melted at $660^{\circ} \mathrm{C}$ in a graphite crucible in an electrical resistance furnace. After complete melting and degassing using a solid dry (hexachloroethane) degasser and argon gas was purged to prevent hydrogen entrapment during melt processing, the alloy was allowed to cool to the semisolid temperature of $601^{\circ} \mathrm{C}$ which was determined using a K-type thermocouple 
TABLE 2: Grain sizes of A356 alloy and A356/MWCNTs composites.

\begin{tabular}{lcccccc}
\hline Samples & A356 & A356/MWCNT & A356/MWCNT & A356/MWCNT & A356/MWCNT & A356/MWCNT \\
\hline MWCNT $($ wt $\%)$ & 0 & 0.5 & 1 & 1.5 & 12.14 & 2 \\
Grain size $(\mu \mathrm{m})$ & 24.36 & 16.22 & 13.83 & \pm 5.47 & 10.34 & 10.15 \\
Standard deviation & \pm 8.95 & \pm 6.32 & \pm 4.87 & \pm 3.12 & \pm 4.84 \\
\hline
\end{tabular}

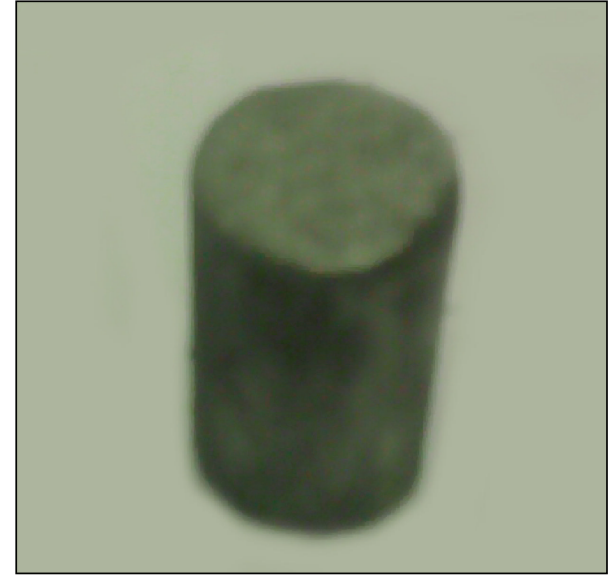

(a)

Figure 1: (a) The pattern of Al/MWCNTs block. (b) Al/MWCNTs small solid billets of reinforcement.

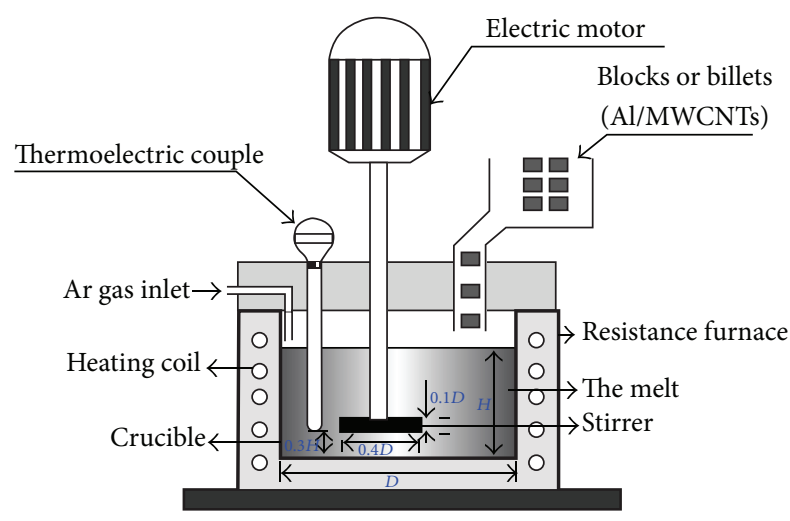

$D$ : diameter of crucible

H: molten metal height

FIGURE 2: Schematic of experimental setup used.

temperature; the solid/liquid fraction was about 0.30 (according to the Scheil equation). Pure magnesium is added to the melt with a $0.75 \%$ weight fraction in order to improve the wettability. It was noticed that, without the addition of magnesium, the MWCNTs were rejected $[15,16]$. Aluminum/MWCNTs blocks or billets introduced into the melt and stirring were continued for 1 minute in semisolid state after the preinfiltration of the preform by the molten metal for 1 minute to produce homogenous mixture at temperature $620^{\circ} \mathrm{C}$. After completing the addition of aluminum/MWCNT billets or blocks, the agitation was stopped and the molten mixture was poured into preheated low carbon steel mould

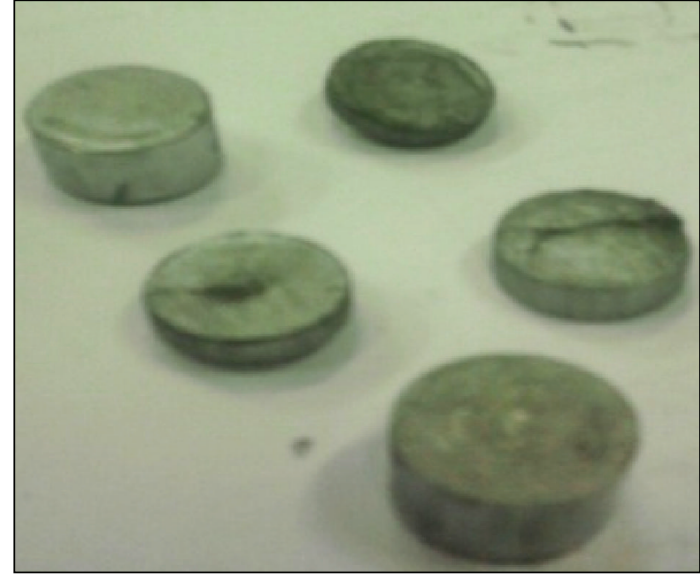

(b)

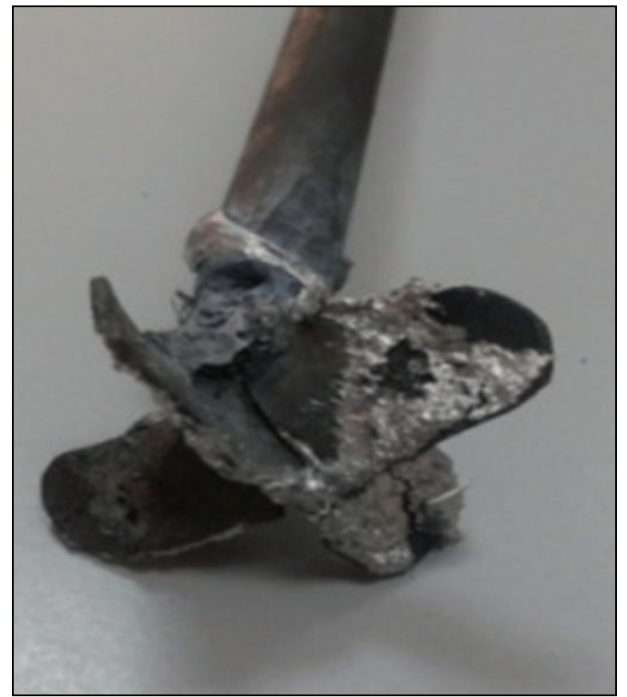

FIgURE 3: The four blades stirrer.

$\left(250^{\circ} \mathrm{C}\right)$ and immediately squeezed during solidification. The pouring temperature for process was $601^{\circ} \mathrm{C}$, and the speed of impeller was $750 \mathrm{rpm}$ using a preheated four blades stirrer shown in Figures 3, 4(a), and 4(b) which show photographs of the mould used for squeezing the nanocomposites and the ingot after squeezing.

2.3. The Analysis of the Sample. The analysis of the A356/MWCNTs composite samples was carried out as follows. Samples from the cast nanocomposite ingots were 


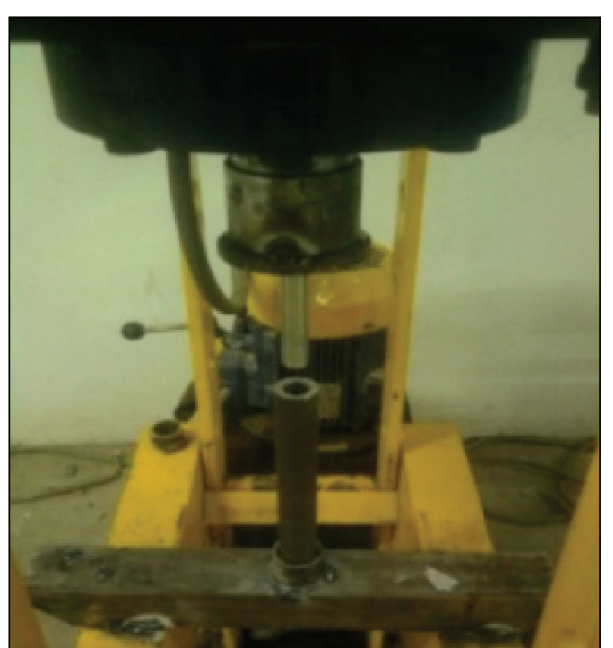

(a)

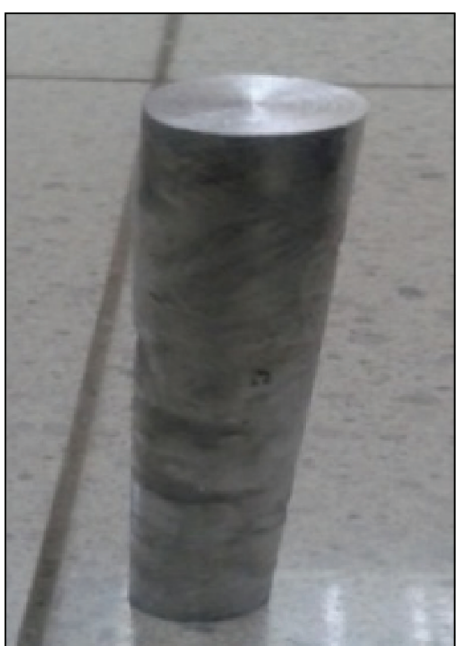

(b)

Figure 4: (a) The mould used to squeeze the nanocomposites and (b) the ingot after squeezing.

cut by an automatic cutter device for microstructural examinations using optical microscopy. Specimens were ground under water on a rotating disc using silicon carbide abrasive discs of increasing finesse up to 2000 grit silicon carbide papers. Then, they were polished using $10 \mu \mathrm{m}$ alumina pastes. The distributive and interfacial states of MWCNTs in the A356 alloy matrices and Al-MWCNTs powder mixture were analyzed with scanning electron microscopes (SEM) (INSPECT S MODEL) equipped with energy dispersive X-ray (EDX) element analysis system to ensure the existence of CNTs. The Brinell hardness values of the samples were measured using a hardened steel ball with $2.5 \mathrm{~mm}$ diameter at a load of $62.5 \mathrm{~kg}$. Ten hardness readings were conducted for each specimen and an average value was calculated. The density of the nanocomposites was measured using the typical Archimedes (water displacement) method. Tensile and compression tests were carried out on composites. The specimens were machined longitudinally from the nanocomposite cast ingots. Mechanical properties of the cast samples were determined by a universal testing machine according to DIN 50125. Compression specimens with a diameter of $10 \mathrm{~mm}$ and height of $20 \mathrm{~mm}$ were used according to ASTM E9-89a. Six samples for repeat tensile and compression tests were cut from each composite ingot and the tensile and compression properties values were averaged from six tests.

\section{Results and Discussion}

3.1. Scanning Electron Microscopic (SEM) Analysis Study of MWCNTs and Milled Powder. The X-ray diffraction pattern of the synthesized CNTs in Figure 5 shows that the strong and sharp reflection peak was found at $26.398^{\circ}$. The presence of this peak in the XRD pattern of CNT indicates the concentric cylindrical nature of graphene sheets nested together and the nanotubes are multiwalled in nature [17]. High resolution transmission electron microscope image of CNTs is shown

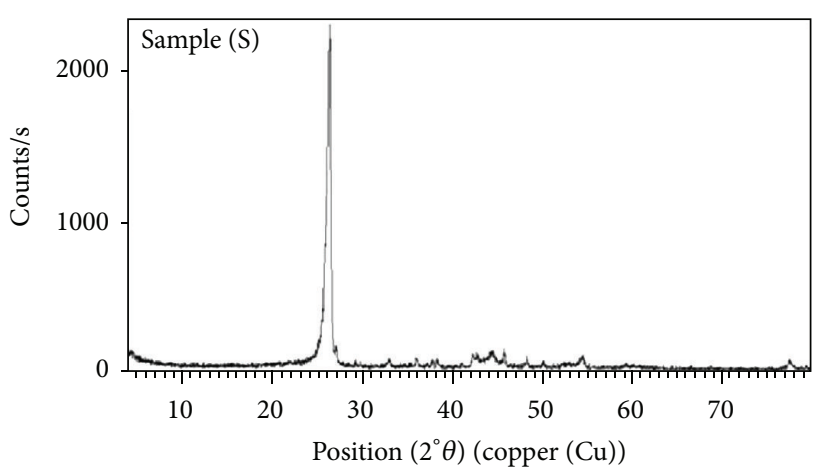

FIGURE 5: XRD pattern of CNTs.

in Figure 6. The figure illustrates the presence of different structures in the sample and that the average size of the MWCNT is about $10 \mathrm{~nm}$ in diameter, $5 \mu \mathrm{m}$ in length, and $90 \%$ in purity, which is in good agreement with the calculated result of the XRD pattern. Figure 8 illustrates the SEM images of aluminum powder with average particle size of $80-100 \mu \mathrm{m}$ before and after being mixing with MWCNTs by ball milling at $200 \mathrm{rpm}$ for 8 hours to increase the homogeneity and dispersibility of MWCNTs in the melt during stirring. It is shown that mechanical interaction between aluminum particles and MWCNTS has been achieved. Higher magnification image of the area marked by the rectangle in Figure 7(b) is shown in Figure 7(c) that reveals the characteristic morphology of the ball milling on the aluminum particle resulting in a very uniform distribution of CNTs in the matrix powder. Due to gradual codeposition of MWCNTs on the aluminum particles, no CNTs agglomerates can be observed in the aluminum-MWCNTs mixed particles. It is expected that, when such particles are injected into the melt, gradually releasing the CNTs into the melt, aluminum-MWCNTs mixed particles CNTs would provide adequate wettability with the molten aluminum alloy and a good bonding with 

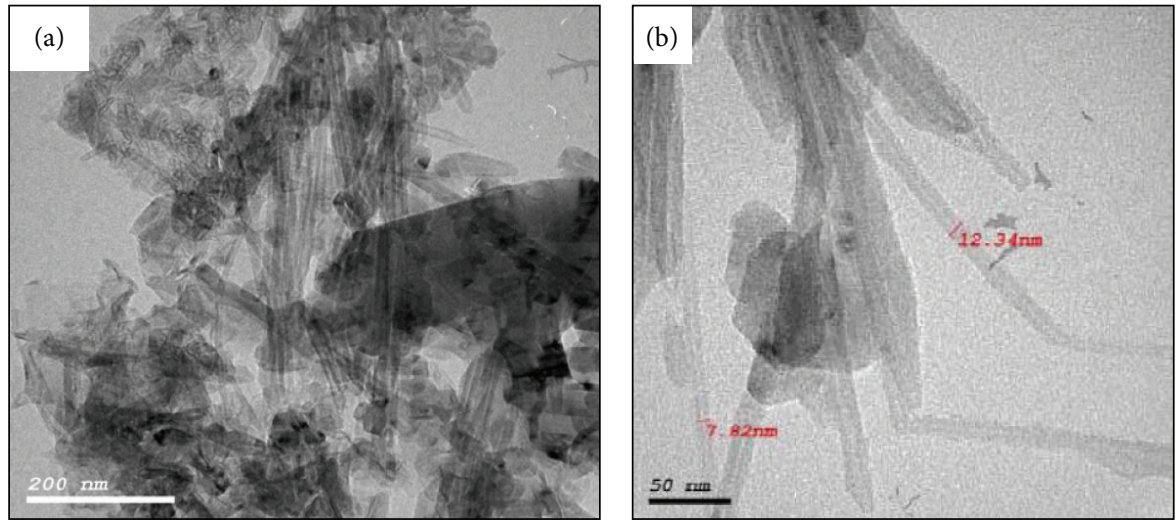

FIGURE 6: HRTEM images of MWCNTs.
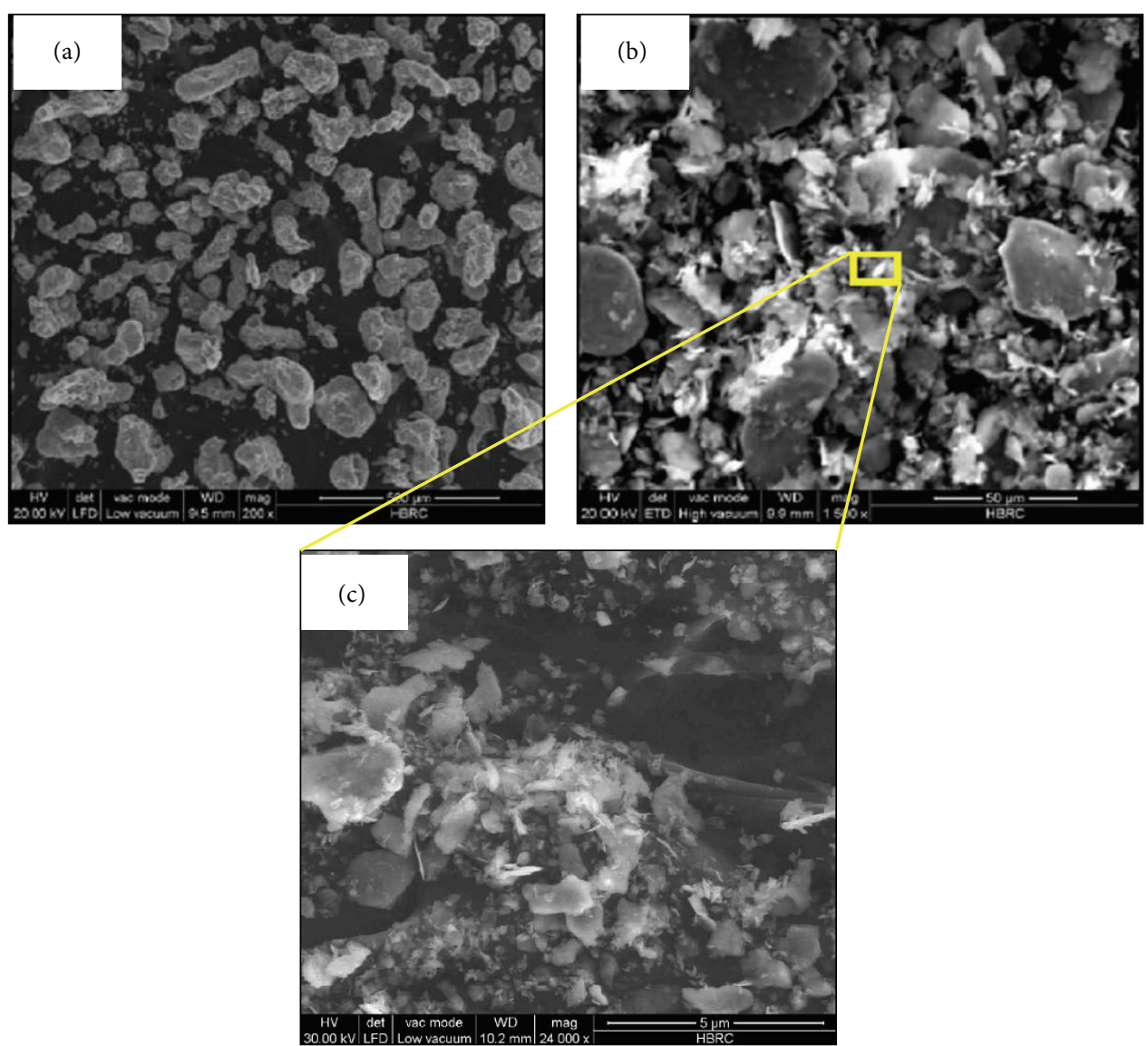

FIGURE 7: SEM images of aluminum particles:. (a) before ball milling; (b) after ball milling $8 \mathrm{~h}$; (c) higher magnification of area marked by rectangle in (b).

the matrix. The stirring action of the stirrer is expected to uniformly distribute the CNTs in the melt.

3.2. Scanning Electron Microscopic (SEM) and XRD Analysis Study of A356/MWCNTs Nanocomposite. Figure 8 shows the XRD pattern of A356/2.5 wt\% MWCNTs nanocomposite, which is less than the limit of XRD resolution; neither CNT nor $\mathrm{Al}_{4} \mathrm{C}_{3}$ peaks are observed in the pattern [12].
It can be observed that the strongest peaks are ascribed to aluminum and silicon is detected. No peaks of aluminum oxide $\left(\mathrm{Al}_{2} \mathrm{O}_{3}\right)$ were observed, indicating the success of this process in fabricating A356/MWCNTs nanocomposite for avoiding oxidation of Al-Si alloy. So, it was difficult to identify the crystal structures of CNTs through XRD $[12,18]$.

The SEM micrographs shown in Figure 9 illustrate the etched fracture surface of samples reinforced with 1.0, 1.5, and $2.5 \mathrm{wt} \%$ MWCNTs and the distribution of MWCNTs 


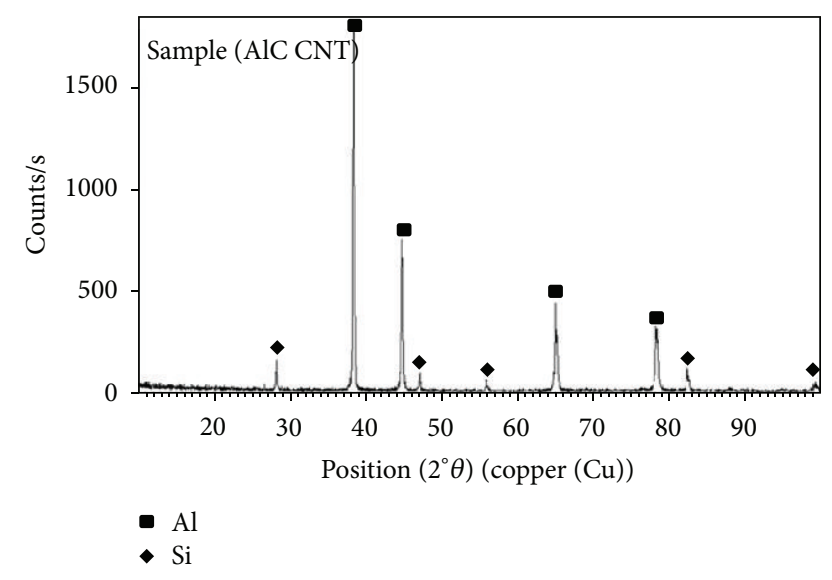

FIGURE 8: XRD pattern of A356/2.5 wt\% MWCNTs nanocomposite.

in different specimens. Figures 9(a) and 9(b) reveal good distribution of nanoparticles and very low agglomeration in the 1.0 and $1.5 \mathrm{wt} \%$ MWCNTs. These samples exhibited good wetting and infiltration by molten matrix alloy. It is expected that wetting between matrix and MWCNTs will be poor which leads to some difficulties as relatively high amounts of CNTs into the alloy because the surface tension of MWCNTs is $100-200 \times 10^{-3} \mathrm{~N} / \mathrm{m}$, while that of molten aluminum silicon alloy is approximately $800 \times 10^{-3} \mathrm{~N} / \mathrm{m}$ [19]. However, the formation of interfacial aluminum carbides $\mathrm{AL}_{4} \mathrm{C}_{3}$ favors the wetting and infiltration of the liquid metal into the MWCNTs porous preform [20]. Figure 9(c) shows that SEM image of the sample was reinforced with $2.5 \mathrm{wt} \%$ MWCNTs; it demonstrates the positions of agglomerations of MWCNTs. This behavior may be attributed to the flotation and unrecovery of some parts of the blocks; this may be due to the relatively large amount of MWCNTs which affected the metal infiltration into the blocks or billets; consequently, samples reinforced with $2.5 \mathrm{wt} \%$ MWCNTs experienced difficulties during infiltration of liquid metal into the MWCNTs; thus small pieces of microsized MWCNTs clusters are located inside the $\alpha$-grains as well as near the eutectic structure and lead to degradation of nanocomposite properties. Also, it has been observed that increasing the weight fraction of the MWCNTs dispersed inside the A356 alloy increases the agglomeration percent. Such low porosity content is attributed to the squeezing process carried out during the solidification of the nanocomposites.

Figures 9(d), 9(e), and 9(f) show that the EDX analysis for $1.0 \%, 1.5$, and $2.5 \mathrm{wt} \%$ reinforced samples confirm the existence of MWCNTs. In case of $2.5 \mathrm{wt} \%$ sample, the high carbon peak may indicate the formation of aluminum carbide, which enhances the interfacial bonding and improves the mechanical properties of the nanocomposite. The existence of oxygen may be attributed to the introduction of metal oxide film into the melt during the stirring process [20].

3.3. Microstructural Observations of A356/MWCNT Nanocomposites. To test if MWCNTs have a role in refinement of grain on A356 Al-Si alloys, optical images were analyzed. As shown in Figure 10 and Table 2, it is observed that the gain sizes in as-cast A356 alloy are obviously greater than those of as-cast A356/MWCNT nanocomposites. Figure 10 shows micrographs of the microstructure of the monolithic A356 alloy as well as the A356/MWCNTs nanocomposites. It is clear from Figure 10(a) that the structure of the monolithic A356 Al-Si alloy without stirring at 0.30 solid fraction consists of primary $\alpha$ phase (white regions) and Al-Si eutectic structure (darker regions). Needle-like primary Si particulates were distributed along the boundaries of the $\alpha$-Al dendrites. Figures 10(b), 10(c), 10(d), 10(e), and 10(f) show the optical microstructure of nanocomposites containing $0.5,1,1.5,2$, and $2.5 \mathrm{wt} \%$ of MWCNT nanocomposites, respectively. The microstructures of the reinforced samples imply remarks for the effect of MWCNTs and also enable it to act as heterogeneous nucleation position that promotes grain refining. Due to mechanical stirring and the addition of MWCNTs, the dendritic structure fragmented and the primary aluminum grains become more uniform and smaller than their corresponding of monolithic samples and with increasing weight fraction of MWCNTs the grain refining increases. The grain sizes of the as-cast A356 Al-Si alloy were approximately $24.36 \pm 8.95 \mu \mathrm{m}$. In contrast, the grain sizes of the A356/MWCNT nanocomposites range between $16.22 \pm 6.32 \mu \mathrm{m}$ and $10.15 \pm 4.84 \mu \mathrm{m}$, which are inversely proportional to the increase of MWCNTs, as indicated in Table 2. The grain shapes of those composites were round and their grain boundaries were wider. These results indicate that MWCNTs have a greater effect on the grain refining of A356 Al-Si alloys. The microstructural changes are attributed to both the stirring action carried out during the addition of the MWCNTs and the heterogeneous nucleation performed by the MWCNTs themselves. The effectiveness of squeezing is to break up agglomerates, help the redistribution of MWCNTs, and improve the microstructure [21].

3.4. Hardness. Figure 11 illustrates the influence of the addition of MWCNTs with different weight fractions on the Rockwell B hardness of A356 alloy. The hardness of cast samples has increased by the addition of MWCNTs, from $59 \pm 3.20$ for the base alloy to $88 \pm 4.02$ for the $2.5 \%$ weight fraction reinforced nanocomposites. It can be observed from the figure that the hardness values have slightly increased for 0.5 and $1 \%$ weight fractions, while they have increased for $1.5,2$, and $2.5 \mathrm{wt} \%$ by a considerable value. The reason for the hardness increasing is that MWCNTs improve in strengthening and hardening the matrix by increasing the matrix alloy dislocation density during cooling to room temperature and due to the difference of the coefficients of thermal expansion between the CNTs and the matrix. This behavior may be also partly attributed to the decrease in the grain size of the A356 matrix of the composite samples by addition of MWCNTs and stirring action. Furthermore, CNTs, like other reinforcements, strengthen the matrix by creation of a high density dislocation during cooling to room temperature due to the difference of the coefficients of thermal expansion between the CNTs and the matrix. Mismatch strains developed at the interfaces of CNTs and 


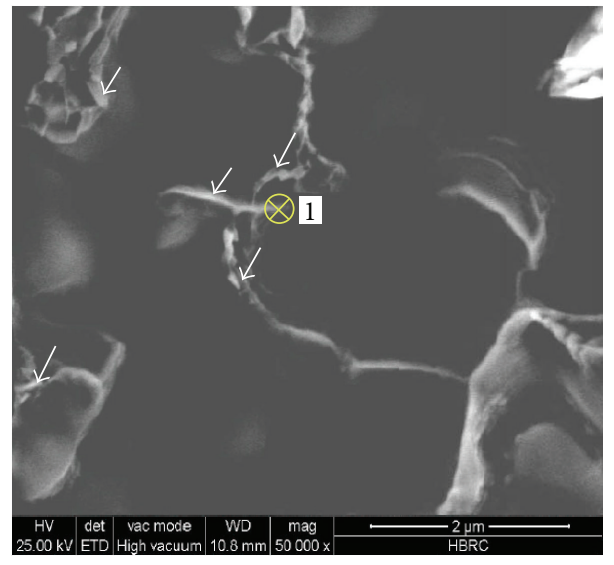

(a)

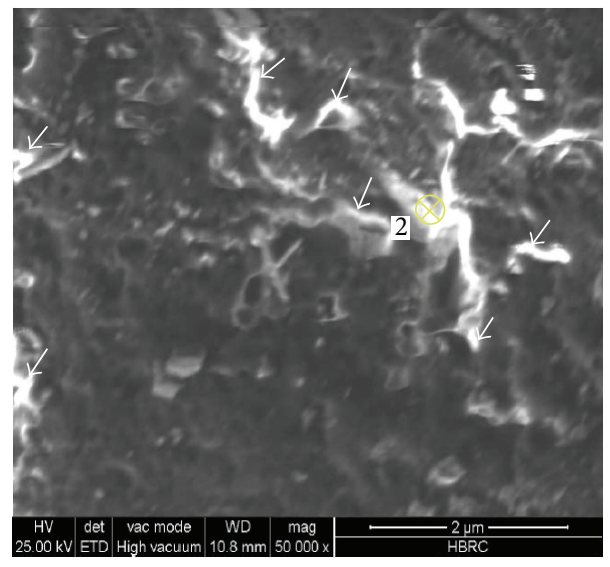

(b)

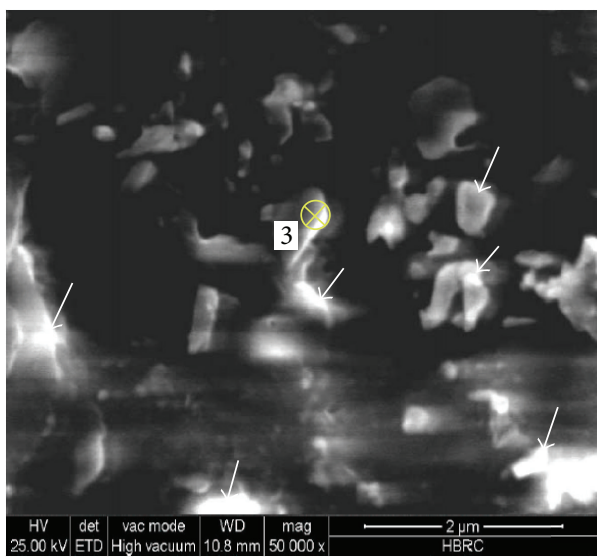

(c)

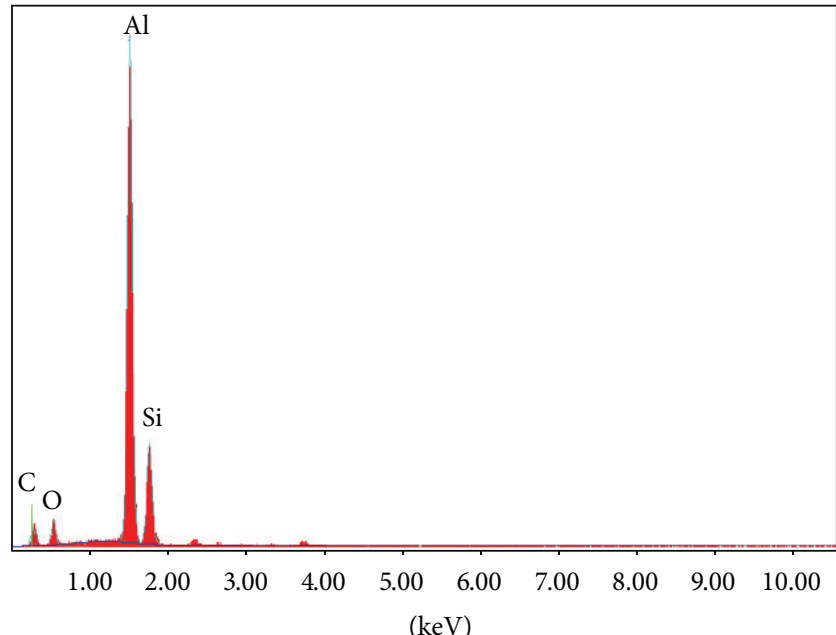

(d)

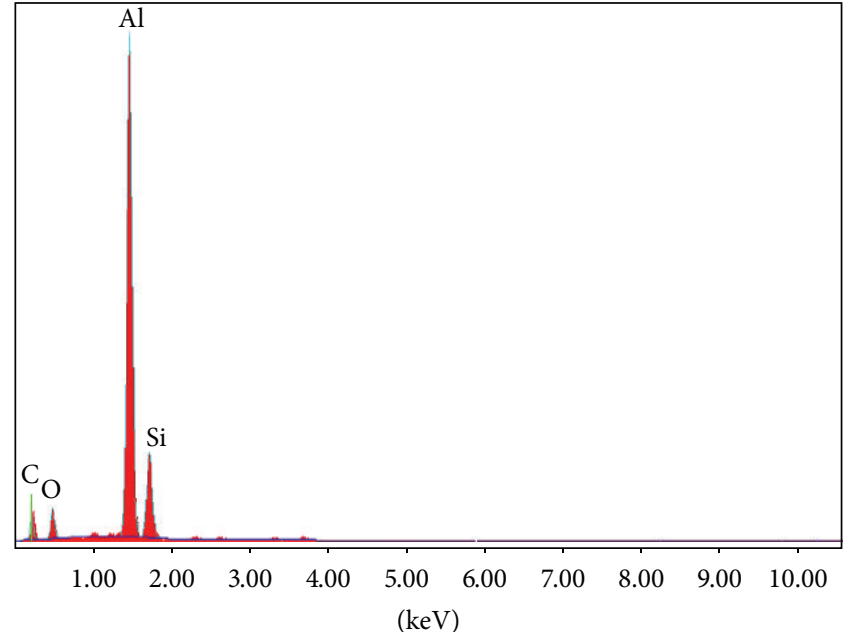

(e)

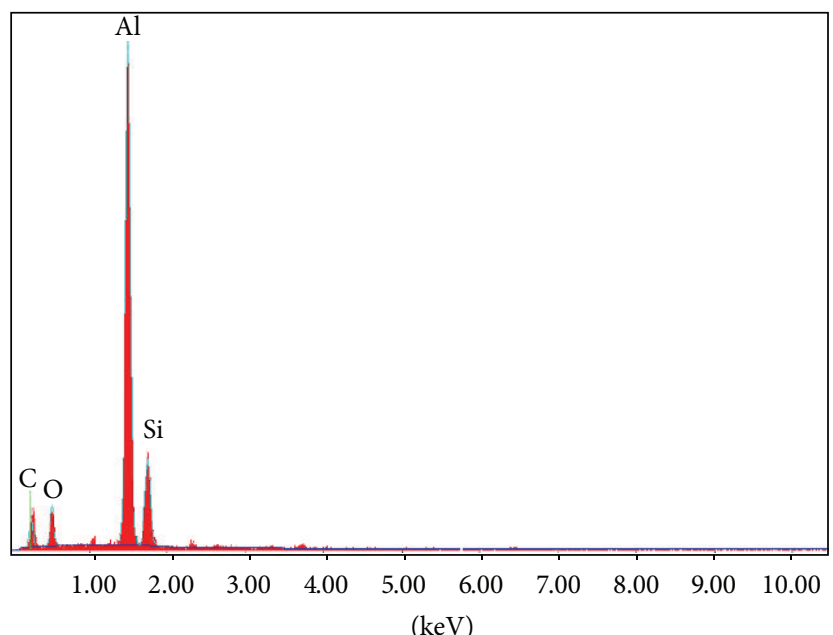

(f)

FIGURE 9: SEM micrographs and EDX quantitative analysis of A356/MWCNTs nanocomposites at the same area (a) 1.0 wt\% MWCNTs and (d) its EDS results of marker number 1, (b) $1.5 \mathrm{wt} \%$ MWCNTs and (e) its EDS results of marker number 2, and (c) $2.5 \mathrm{wt} \% \mathrm{MWCNTs}$ and (f) its EDS results of marker number 3 fabricated by using a combination of rheocasting and squeeze casting techniques. 


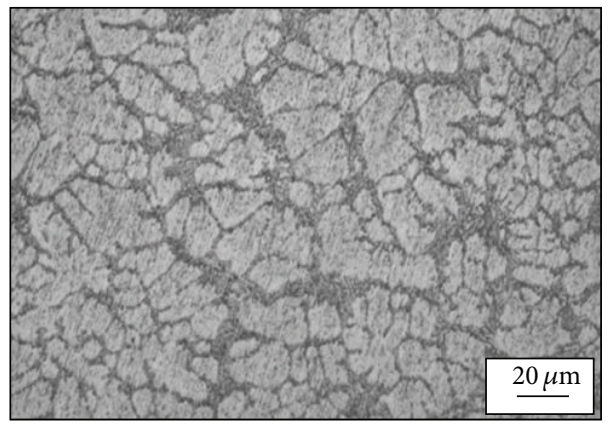

(a)

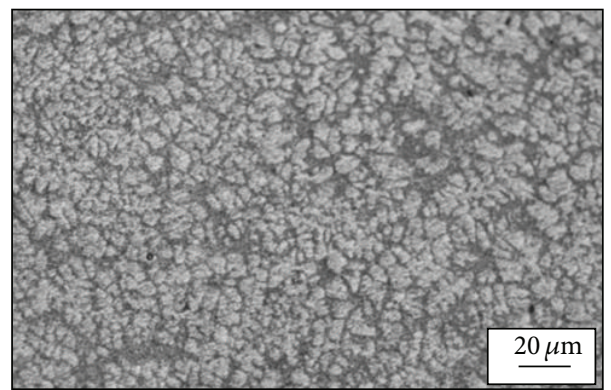

(c)

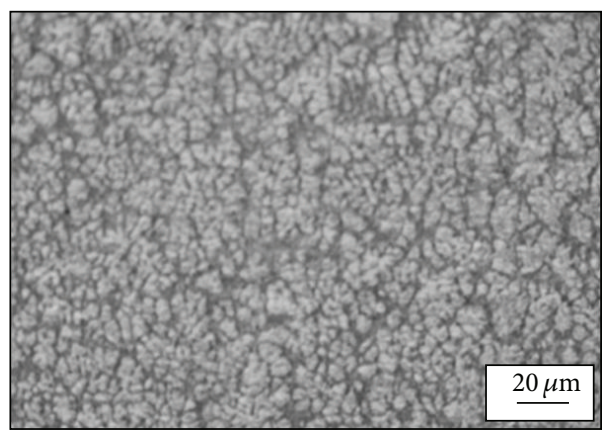

(e)

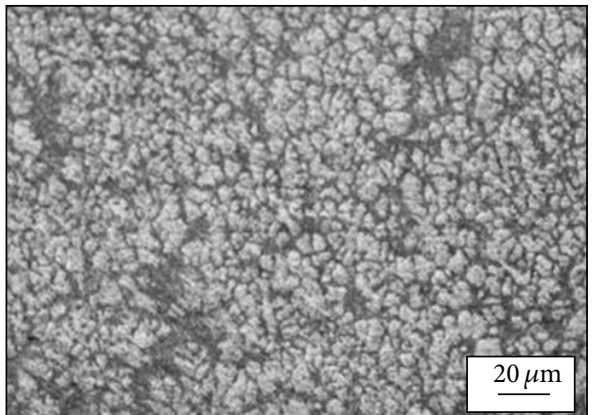

(b)

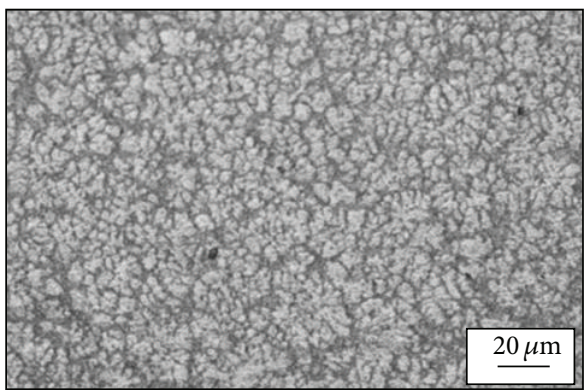

(d)

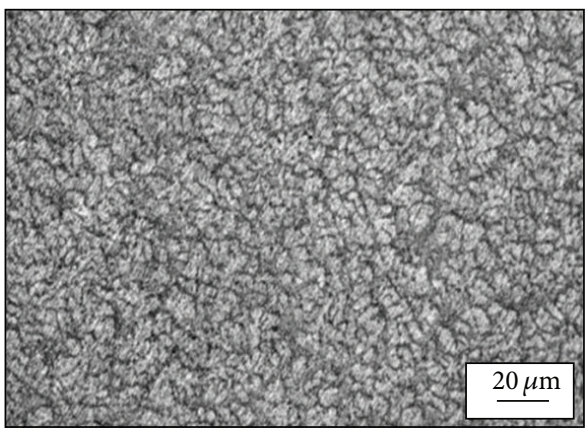

(f)

Figure 10: Optical micrographs for (a) A356 monolithic aluminum alloy; (b) A356/0.5 wt\% MWCNTs nanocomposites; (c) A356/1 wt\% MWCNTs nanocomposites; (d) A356/1.5 wt\% MWCNTs; (e) A356/2 wt\% MWCNTs nanocomposites; (f) A356/2.5 wt\% MWCNTs nanocomposites.

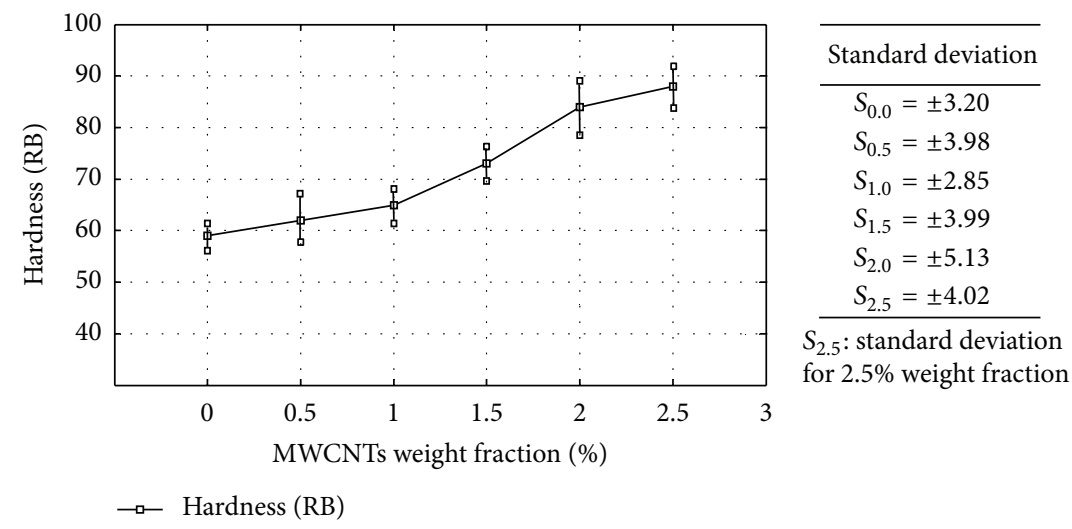

FIGURE 11: Effect of MWCNTs different weight fractions on hardness of the A356 alloy. 


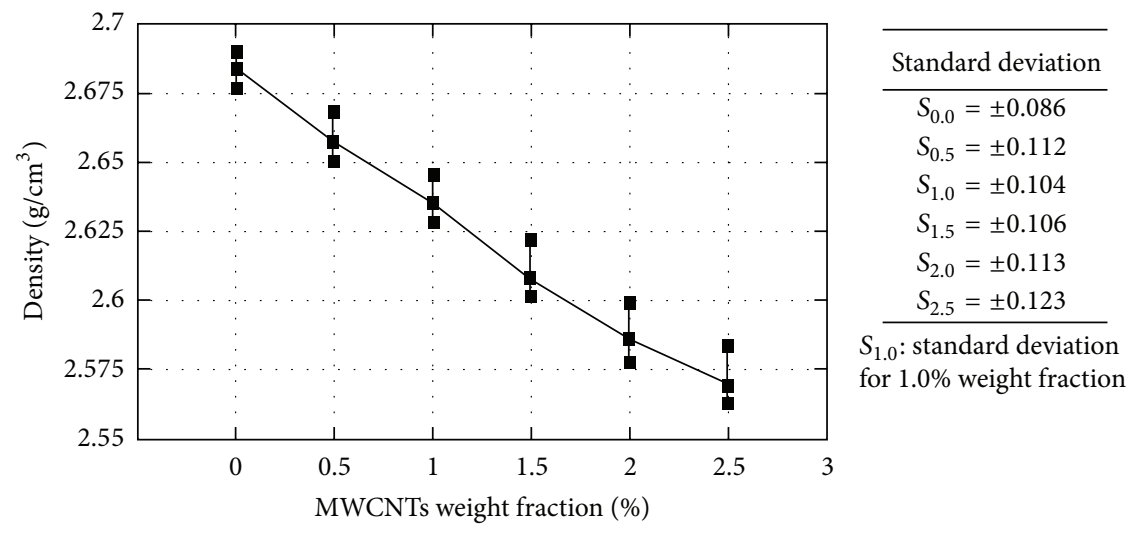

FIGURE 12: Effect of MWCNTs different weight fractions on densities of different samples.

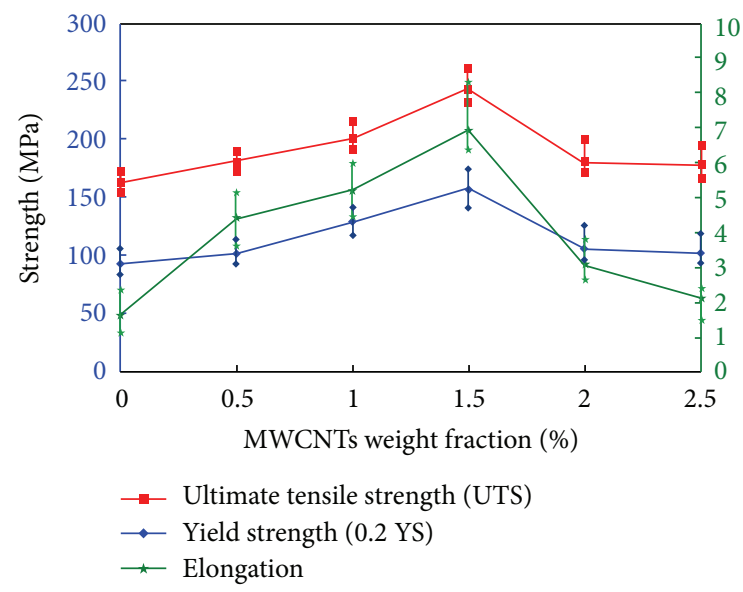

\begin{tabular}{|c|c|c|}
\hline $\begin{array}{c}\text { Y.S } \\
(\mathrm{MPa})\end{array}$ & $\begin{array}{l}\text { U.T.S } \\
(\mathrm{MPa})\end{array}$ & $\begin{array}{c}\text { Elongation } \\
(\%)\end{array}$ \\
\hline $\begin{array}{l}\text { Standard } \\
\text { deviation } \\
\end{array}$ & $\begin{array}{l}\text { Standard } \\
\text { deviation }\end{array}$ & $\begin{array}{l}\text { Standard } \\
\text { deviation }\end{array}$ \\
\hline$S_{0.0}= \pm 6.94$ & $S_{0.0}= \pm 3.98$ & $S_{0.0}= \pm 0.63$ \\
\hline$S_{0.5}= \pm 6.88$ & $S_{0.5}= \pm 4.39$ & $S_{0.5}= \pm 0.73$ \\
\hline$S_{1.0}= \pm 11.60$ & $S_{1.0}= \pm 5.32$ & $S_{1.0}= \pm 0.88$ \\
\hline$S_{1.5}= \pm 8.40$ & $S_{1.5}= \pm 8.28$ & $S_{1.5}= \pm 0.79$ \\
\hline$S_{2.0}= \pm 6.21$ & $S_{2.0}= \pm 7.39$ & $S_{2.0}= \pm 0.83$ \\
\hline$S_{2.5}= \pm 6.41$ & $S_{2.5}= \pm 7.24$ & $S_{2.5}= \pm 0.84$ \\
\hline
\end{tabular}

FIgURE 13: Tensile properties of as-cast A356 alloy and A356/MWCNTs nanocomposites.

the matrix obstruct the movement of the dislocations, resulting in the improvement of the hardness of the composites [12]. Further investigation will be done using transmission electron microscopy (TEM) and investigations will be done in the future to precisely detect the mechanism responsible for the simultaneous increase in hardness and study to ensure the mismatch strains developed at the interfaces of CNTs and matrix and the formation of aluminum carbide. The density results of A356 alloy and A356/MWCNT nanocomposites are shown in Figure 12. It was observed that the density of the nanocomposites decreases with increasing weight percentages of MWCNTs. According to observation by Landry et al. [19] during sintering and cooling the distribution of dislocations within the matrix of the composites would not be uniform and there will be higher density near the reinforcing particles. The reason for the decrease in the density is due to the addition of light weight and high volume CNTs compared to the matrix material, which increases the porosity of the nanocomposite samples [12].

\subsection{Mechanical Properties}

3.5.1. Tensile Test. Figure 13 shows the yield strength $(0.2 \%$ YS), ultimate tensile strength (UTS), and elongation of as-cast
A356 alloy and A356/MWCNTs nanocomposites. It can be observed that the tensile strength has increased with the increase of MWCNT content reaching optimal value at $1.5 \mathrm{wt} \%$ MWCNTs. The CNTs content increased to optimal value and the mechanical properties of the A356/MWCNTs decreased. It can be seen that the ultimate tensile strength and yield strength of the composites are simultaneously enhanced compared to those of as-cast A356 alloy. The tensile strength increases from $162.25 \pm 3.98 \mathrm{MPa}$ for the base alloy to an average value of $242.65 \pm 8.28 \mathrm{MPa}$ for $1.5 \mathrm{wt} \% \mathrm{MWCNTs}$ weight fraction reinforced composite. At the optimal amount of multiwall carbon nanotubes $(1.5 \mathrm{wt} \%)$, the ultimate tensile strength and yield strength of the composite were enhanced by $50 \%$ and $60 \%$, respectively, compared to the alloy matrix. The increase in the mechanical properties can partly be attributed to coupled effects of increase in grain boundary area due to grain refinement, the strong thermal stress at the interface induced by the large difference of coefficient of thermal expansion between the matrix and MWCNTs reinforcement, and the effective transfer of tensile load to the uniform distribution of MWCNTs. However, increasing the amount of MWCNTs above $1.5 \mathrm{wt} \%$ was found to deteriorate the tensile strength of the composite to a value of $180.75 \pm 7.24 \mathrm{MPa}$ for $2.5 \mathrm{wt} \% \mathrm{MWCNTs}$ reinforced 


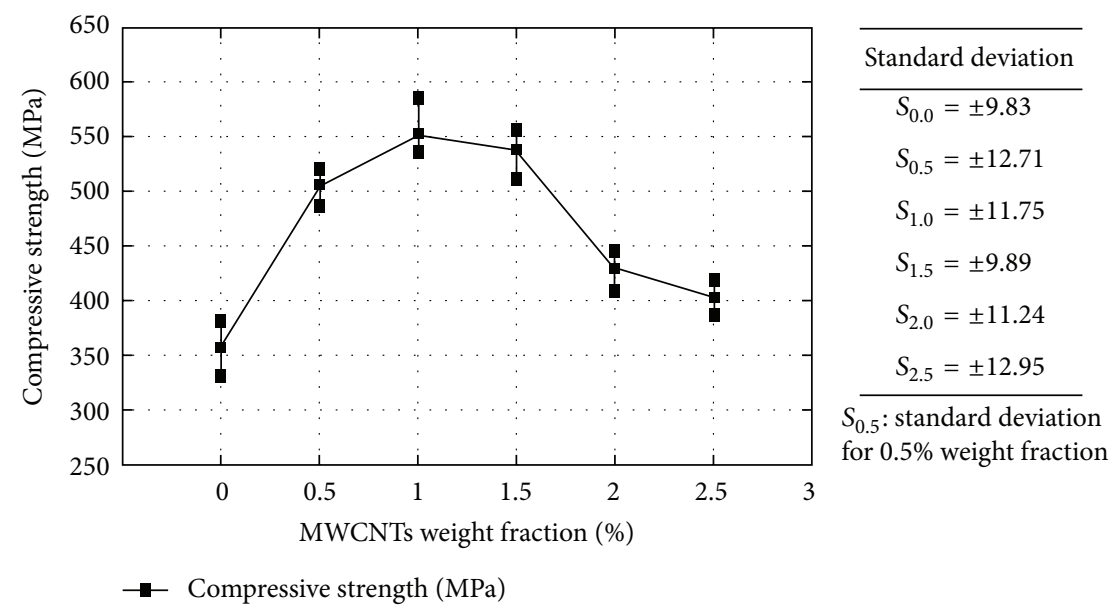

FIGURE 14: Compressive strength of A356/MWCNTs specimens of different MWCNTs contents fabricated by using a combination of rheocasting and squeeze casting techniques.

composite. The lower value of strength for the $2.5 \mathrm{wt} \%$ reinforced composite may be attributed to difficulties of hydrogen entrapment during the reinforcement addition. Adding of MWCNTs above the optimal value will make the composite become more brittle. This may be the result of greater agglomeration of nanoparticles and higher degree of microporosity present in the nanocomposite with higher MWCNTs content. As shown in Figure 13, the addition of MWCNTs leads to the improvement of the ductility and decrease with the increase MWCNTs content above the optimal value. The elongation percentage increased from $1.65 \pm 0.63 \%$ to $4.42 \pm 0.73 \%$ and jumped to $5.26 \pm 0.88 \%$ for the $0.5 \%$ and $1.0 \%$ reinforced composites, respectively. Samples reinforced with $1.5 \%$ showed the highest elongation percentage, increasing from $1.65 \pm 0.63 \%$ for the base alloy up to $6.93 \pm 0.79 \%$. The mechanical properties of all the casting samples are illustrated in Figure 13. The simultaneous increase of composite ductility with tensile strength is attributed to slip mode transition produced by the presence of MWCNTs which depends on the A356/MWCNTs interaction $[22,23]$. As MWCNTs represent very fine precipitates, the plastic deformation changed from dislocation reinforcement shearing to dislocation reinforcement by passing. But, due to the high strength of CNTs, the MWCNTs impede the dislocation motion and collapse them around the A35/MWCNTs interface $[24,25]$. The activation of such cross-slip modes is responsible for the increased ductility, which influence the effectiveness of squeezing into break up agglomerates and distribute particles. The results obtained are similar to those of other research works on magnesium and aluminum alloys $[26,27]$. Samples reinforced with $2.5 \mathrm{wt} \%$ MWCNTs also have lower values of elongation percentage, resembling the same behavior of tensile strength. The reduction in ductility may refer to the unrecovered and agglomerated CNTs as explained in SEM analysis. The occurrence of dimples suggests strong interfacial bonding between the matrix and reinforcement in Section 3.6.1 fractographs of the tensile test specimens. Further TEM investigations will be done in the future to precisely detect the mechanism responsible for the simultaneous increase in tensile strength and ductility.

3.5.2. Compression Test. The compressive strength of a nanocomposite can primarily be attributed to grain refinement, presence of reasonably distributed MWCNTs, dislocation generation due to elastic modulus mismatch and coefficient of thermal expansion mismatch between the matrix and reinforcement phase, and load transfer from matrix to reinforcement phase [22-26]. The results presented in Figure 14 show that the compressive strength of nanocomposites is greater than that of monolithic alloy at optimal value $1.0 \mathrm{wt} \%$ as MWCNTs are more effective in strengthening the composites. Moreover, compressive strength of nanocomposites at optimal value is more than that of monolithic alloy due to the effect of grain size. Grain-refining effects were observed by adding MWCNTs. The improvement of the mechanical properties of the composites is contributed to excellent mechanical properties of CNTs. The CNTs content increased above a critical value. Excessive CNT content can cause unwanted effects such as the formation of carbide. Presence of interfacial phases can play a supporting medium to transfer stress from the matrix to the CNTs during the failure part of the deformation in compression testing and can result in weakening of the composites.

\subsection{Fractographic Examination}

3.6.1. Fractographs of the Tensile Test Specimens. The SEM micrograph for fracture surface of A356 Al-Si alloy and A356/MWCNTs nanocomposites specimens containing different MWCNTs contents after tensile tests is shown in Figure 15. The fracture surfaces of A356 monolithic alloy as shown in Figure 15(a) displayed cleavage planes as well as a slight number of dimples which represented a mixture of brittle and ductile fracture and Figure 15(b) displayed cleavage planes as well as a number of dimples which represented a mixture of brittle and ductile fractures. However, the fracture 

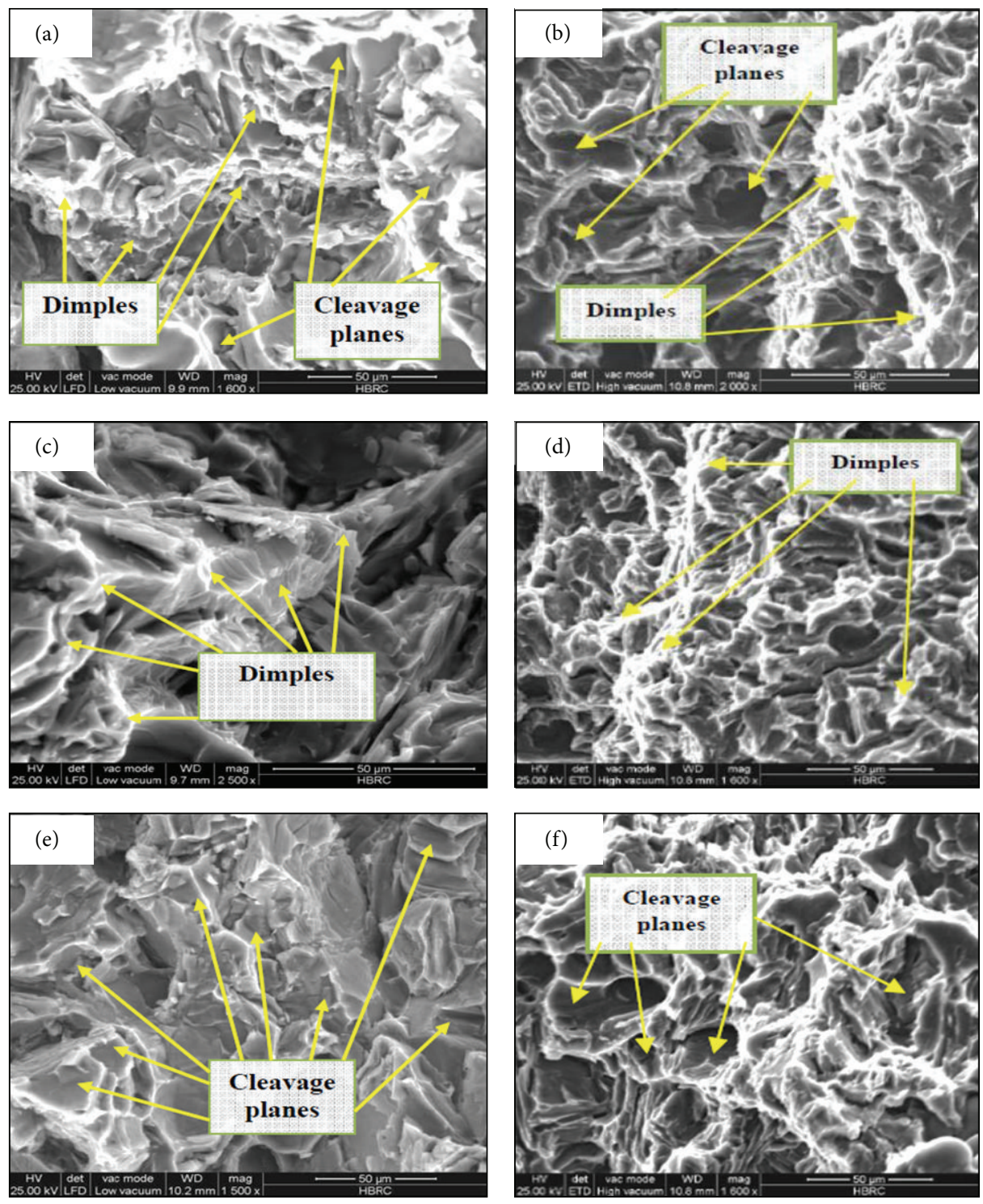

FIGURE 15: Fracture surface micrographs of A356/MWCNTs nanocomposite specimens containing different MWCNTs contents: (a) sample of A356, (b) sample of $0.5 \mathrm{wt} \%$ MWCNTs, (c) sample of $1.0 \mathrm{wt} \%$ MWCNTs, (d) sample of $1.5 \mathrm{wt} \%$ MWCNTs, (e) sample of $2.0 \mathrm{wt} \% \mathrm{MWCNTs}$, and (f) sample of $2.5 \mathrm{wt} \%$ MWCNT.

surface of the sample tested containing $1.0 \mathrm{wt} \%$ and $1.5 \mathrm{wt} \%$ MWCNTs as shown in Figures 15(c) and 15(d) displayed a large number of dimples which represented a ductile fracture, which corresponds to their better ductility. The fracture surface of sample tested containing $2.0 \mathrm{wt} \%$ and $2.5 \mathrm{wt} \%$ MWCNTs as shown in Figures 15(e) and 15(f) displays cleavage planes associated with brittle fracture at highest content of CNTs. Therefore, when the MWCNT content increases, the A356/MWCNTs composite will become more brittle. Finally, the unique mechanical properties of CNTs and the special addition technique employed in this study have resulted in significant improvement of the mechanical properties as well as the fracture mode of A356/MWCNTs nanocomposites. Presence of interfacial phases can play an important role as a supporting medium to transfer stress from the matrix to the CNTs during the instability (necking) part of the deformation in tensile testing and can result in weakening of the composites $[28,29]$.

3.6.2. Analysis of MMNCs Compression Specimens. In general, aluminum alloy material exhibits ductile deformation and fracture during plastic deformation, as shown in Figure 16(a). In contrast, MMNCs exhibit brittle fracture due to reinforcement. Different directions of the slip plane were observed in one specimen (2.5 wt\% MWCNTs); Figures 16(b) and 17(a) show SEM images of the fracture surface of A356 alloy. Figures 17(b), 17(c), 17(d), 17(e), and 17(f) show SEM images of the fracture surface of nanocomposites containing $0.5,1,1.5,2$, and $2.5 \mathrm{wt} \%$ of MWCNT nanocomposites after 

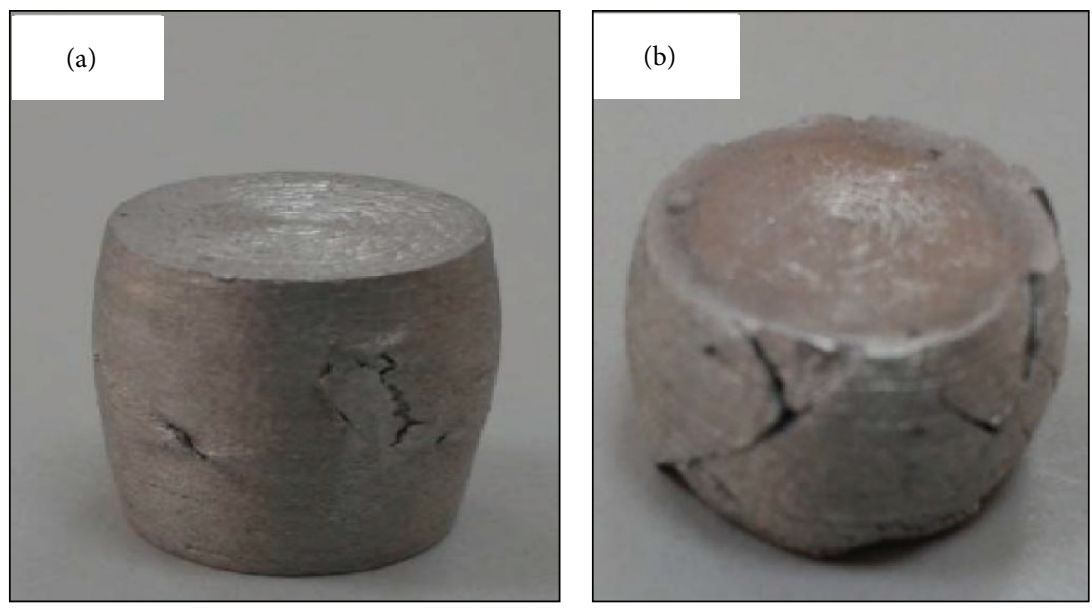

FIGURE 16: The picture of fracture specimen after compression: (a) A356 aluminum specimen and (b) composite specimen 2.5 wt $\%$ MWCNTs.
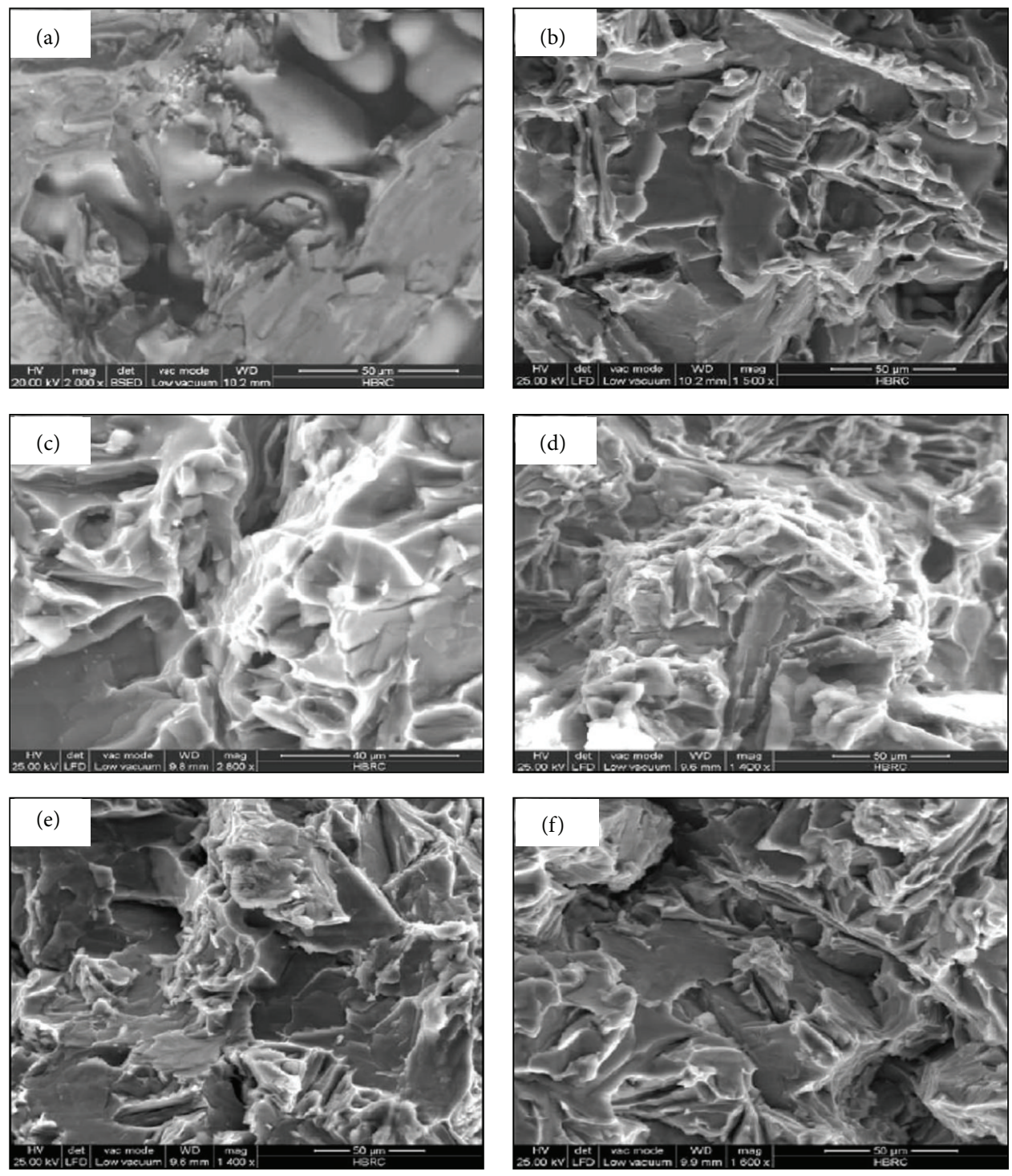

Figure 17: SEM images of the fracture surface of (a) A356, (b) A356/0.5 wt\% MWCNTs, (c) A356/1.0 wt\% MWCNTs, (d) A356/1.5 wt\% MWCNTs, (e) A356/2.0 wt\% MWCNTs, and (f) A356/2.5 wt\% MWCNTs composite after compression. 
compression, respectively. It is obvious that the A356 alloy has a rather smooth fracture surface with several sharp breaking edges, while the fracture surface of MWNTs reinforced A356 composite exhibits a lot of dimples, which indicates a more ductile behavior of the composite [11]. CNTs do not mix well with aluminum alloy due to poor wettability. When adding the CNTs to the molten aluminum, the CNTs immediately float due to the difference in specific gravity and poor wettability. Therefore, using CNTs is an effective method for fabricating A356/MWCNTs aluminum alloy MMNCs.

\section{Conclusions}

Throughout the experimental results and analysis of this work, the following conclusions could be withdrawn.

(i) A356 aluminum alloys reinforced with multiwall carbon nanotubes (MWCNTs) in weight percentages of $0,0.5,1,1.5,2$, and $2.5 \mathrm{wt} \%$ were successfully produced by a novel processing approach using a combination of rheocasting and squeeze casting techniques.

(ii) Well uniformly dispersed MWCNTs into the melt resulted in good distribution and less agglomeration of CNTs in the matrices of the produced A356/MWCNTs nanocomposites which resulted in improved mechanical properties as the yield and ultimate tensile strengths of the castings.

(iii) The A356 matrix alloy reinforced with $1.5 \mathrm{wt} \%$ MWCNTs revealed the ultimate tensile and yield strength properties and elongation percentage. The ultimate tensile strength of nanocomposite occurred with an increase from $162.25 \pm 3.98 \mathrm{MPa}$ for monolithic alloy to a value of $242.65 \pm 8.28 \mathrm{MPa}$; the ultimate tensile strength and yield strength of $1.5 \mathrm{wt} \%$ A356/MWCNTs nanocomposite are enhanced by $50 \%$ and $60 \%$, respectively. This improvement can be referred to the uniform distribution of reinforcement and grain refinement of aluminum matrix and the elongation percentage from $1.65 \pm 0.63 \%$ to $6.93 \pm 0.79 \%$.

(iv) Hardness measurement revealed also an improvement compared to the A356 monolithic alloy. As the weight fraction of MWCNTs increases, the hardness increases. The base alloy hardness of $59 \pm 3.20$ Rockwell $\mathrm{B}$ has been increased to a maximum value $88 \pm 4.02$ for the alloy reinforced with $2.5 \%$ weight fraction of MWCNTs.

(v) The compressive strengths of MMNCs have been increased with increasing MWCNTs weight fraction compared to A356 aluminum alloy at optimal value of $1.0 \mathrm{wt} \%$. Large amount of CNTs adversely affected the material strength due to agglomeration or poor wettability with the matrix.

\section{Conflict of Interests}

The authors declare that there is no conflict of interests regarding the publication of this paper.

\section{References}

[1] K. Lee, Y. N. Kwon, and S. Lee, "Correlation of microstructure with mechanical properties and fracture toughness of A356 aluminum alloys fabricated by low-pressure-casting, rheo-casting, and casting-forging processes," Engineering Fracture Mechanics, vol. 75, no. 14, pp. 4200-4216, 2008.

[2] C. R. Pesi, C. S. Veinovi, and C. R. Pavlovi, "Application of aluminium alloys in production of engines and compressors," Mobility \& Vehicles Mechanics, vol. 30, pp. 85-105, 2004, special edition.

[3] A. Vencl, I. Bobic, S. Arostegui, B. Bobic, A. Marinković, and M. Babić, "Structural, mechanical and tribological properties of A356 aluminium alloy reinforced with $\mathrm{Al}_{2} \mathrm{O}_{3}, \mathrm{SiC}$ and $\mathrm{SiC}+$ graphite particles," Journal of Alloys and Compounds, vol. 506, no. 2, pp. 631-639, 2010.

[4] S. A. Sajjadi, H. R. Ezatpour, and H. Beygi, "Microstructure and mechanical properties of $\mathrm{Al}-\mathrm{Al}_{2} \mathrm{O}_{3}$ micro and nano composites fabricated by stir casting," in Proceedings of the 14th National Conference on Materials Science and Engineering, pp. 325-332, Tehran, Iran, 2010.

[5] S. A. Sajjadi, M. Torabi Parizi, H. R. Ezatpour, and A. Sedghi, "Fabrication of A356 composite reinforced with micro and nano $\mathrm{Al}_{2} \mathrm{O}_{3}$ particles by a developed compocasting method and study of its properties," Journal of Alloys and Compounds, vol. 511, no. 1, pp. 226-231, 2012.

[6] A. Mazahery, H. Abdizadeh, and H. R. Baharvandi, "Development of high-performance A356/nano- $\mathrm{Al}_{2} \mathrm{O}_{3}$ composites," Materials Science and Engineering A, vol. 518, no. 1-2, pp. 61-64, 2009.

[7] I. El-Mahallawi, H. Abdelkader, L. Yousef, A. Amer, J. Mayer, and A. Schwedt, "Influence of $\mathrm{Al}_{2} \mathrm{O}_{3}$ nano-dispersions on microstructure features and mechanical properties of cast and T6 heat-treated Al Si hypoeutectic Alloys," Materials Science \& Engineering A, vol. 556, pp. 76-87, 2012.

[8] S. Iijima, "Helical microtubules of graphitic carbon," Nature, vol. 354, pp. 56-58, 1991.

[9] M. Yu, B. S. Files, S. Arepalli, and R. S. Ruoff, “Tensile loading of ropes of single wall carbon nanotubes and their mechanical properties," Physical Review Letters, vol. 84, no. 24, pp. 5552 $5555,2000$.

[10] S. R. Bakshi, V. Singh, S. Seal, and A. Agarwal, "Aluminum composite reinforced with multiwalled carbon nanotubes from plasma spraying of spray dried powders," Surface and Coatings Technology, vol. 203, no. 10-11, pp. 1544-1554, 2009.

[11] Q. Li, A. Viereckl, C. A. Rottmair, and R. F. Singer, "Improved processing of carbon nanotube/magnesium alloy composites," Composites Science and Technology, vol. 69, no. 7-8, pp. 1193$1199,2009$.

[12] B. Abbasipour, B. Niroumand, and S. M. M. Vaghefi, "Compocasting of A356-CNT composite," Transactions of Nonferrous Metals Society of China, vol. 20, no. 9, pp. 1561-1566, 2010.

[13] X. Zeng, G. Zhou, Q. Xu, Y. Xiong, C. Luo, and J. Wu, "A new technique for dispersion of carbon nanotube in a metal melt," Materials Science and Engineering A, vol. 527, no. 20, pp. 5335$5340,2010$.

[14] H. Sevik and S. C. Kurnaz, "Properties of alumina particulate reinforced aluminum alloy produced by pressure die casting," Materials and Design, vol. 27, no. 8, pp. 676-683, 2006.

[15] H. H. Kim, J. S. S. Babu, and C. G. Kang, "Fabrication of A356 aluminum alloy matrix composite with $\mathrm{CNTs} / \mathrm{Al}_{2} \mathrm{O}_{3}$ hybrid 
reinforcements," Materials Science \& Engineering A, vol. 573, pp. 92-99, 2013.

[16] S. Chatterjee and A. B. Mallick, "Challenges in manufacturing aluminium based metal matrix nanocomposites via stir casting route," Materials Science Forum, vol. 736, pp. 72-80, 2013.

[17] M. S. S. Saravanan, S. P. K. Babu, K. Sivaprasad, and M. Jagannatham, "Technoeconomics of carbon nanotubes produced by open air arc discharge method," Journal of Engineering Science and Technology, vol. 2, no. 5, pp. 100-108, 2010.

[18] S. R. Bakshi, A. K. Keshri, V. Singh, S. Seal, and A. Agarwal, "Interface in carbon nanotube reinforced aluminum silicon composites: thermodynamic analysis and experimental verification," Journal of Alloys and Compounds, vol. 481, no. 1-2, pp. 207-213, 2009.

[19] K. Landry, S. Kalogeropoulou, and N. Eustathopoulos, "Wettability of carbon by aluminum and aluminum alloys," Materials Science and Engineering A, vol. 254, no. 1-2, pp. 99-111, 1998.

[20] I. S. El-Mahallawi, K. Eigenfeld, F. H. Kouta et al., "Synthesis and characterization of new cast $\mathrm{A} 356 /\left(\mathrm{Al}_{2} \mathrm{O}_{3}\right) \mathrm{P}$ metal matrix nano-composites," in Proceeding of the 2nd Multifunctional Nanocomposites \& Nanomaterials, International Conference \& Exhibition, pp. 87-92, Cairo, Egypt, January 2008.

[21] S. Y. El-Kady, T. S. Mahmoud, and M. A. Sayed, "Elevated temperatures tensile characteristics of cast $\mathrm{A} 356 / \mathrm{Al}_{2} \mathrm{O}_{3}$ nanocomposites fabricated using a combination of rheocasting and squeeze casting techniques," Materials Sciences and Applications, vol. 2, pp. 390-398, 2011.

[22] R. J. Arsenault and N. Shi, "Dislocation generation due to differences between the coefficients of thermal expansion," Materials Science and Engineering, vol. 81, pp. 175-187, 1986.

[23] S. R. Bakshi and A. Agarwal, "An analysis of the factors affecting strengthening in carbon nanotube reinforced aluminum composites," Carbon, vol. 49, no. 2, pp. 533-544, 2011.

[24] G. E. Dieter, Mechanical Metallurgy, McGraw-Hill, London, UK, 1988.

[25] R. M. Rashad, O. M. Awadallah, and A. S. Wifi, "Effect of MWCNTs content on the characteristics of A356 nanocomposite," Journal of Achievements in Materials and Manufacturing Engineering, vol. 2, pp. 74-80, 2013.

[26] R. George, K. T. Kashyap, R. Rahul, and S. Yamdagni, "Strengthening in carbon nanotube/aluminium (CNT/Al) composites," Scripta Materialia, vol. 53, no. 10, pp. 1159-1163, 2005.

[27] J. Wei, C. S. Goh, S. M. L. Nai, and G. J. Bi, "Simultaneous enhancement in strength and ductility by reinforcing magnesium with carbon nanotubes," Materials Science and Engineering A, vol. 423, no. 1-2, pp. 153-156, 2006.

[28] M. Paramsothy, M. Gupta, J. Chan, and R. Kwok, "Carbon nanotube addition to simultaneously enhance strength and ductility of hybrid AZ31/AA5083 alloy," Materials Sciences and Applications, vol. 2, pp. 20-29, 2011.

[29] L. Ci, Z. Ryu, N. Y. Jin-Phillipp, and M. Rühle, "Investigation of the interfacial reaction between multi-walled carbon nanotubes and aluminum," Acta Materialia, vol. 54, no. 20, pp. 5367-5375, 2006. 

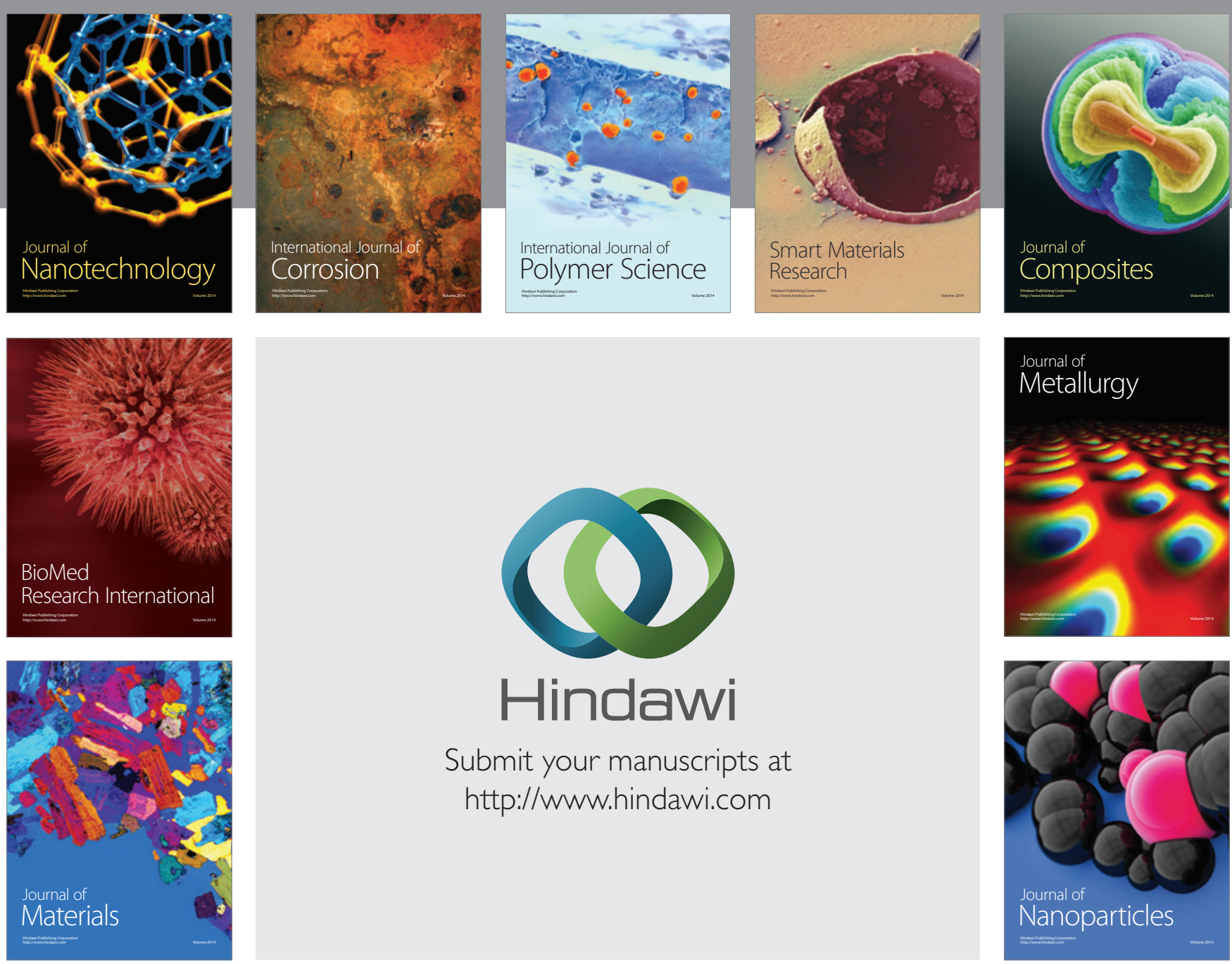

Submit your manuscripts at http://www.hindawi.com
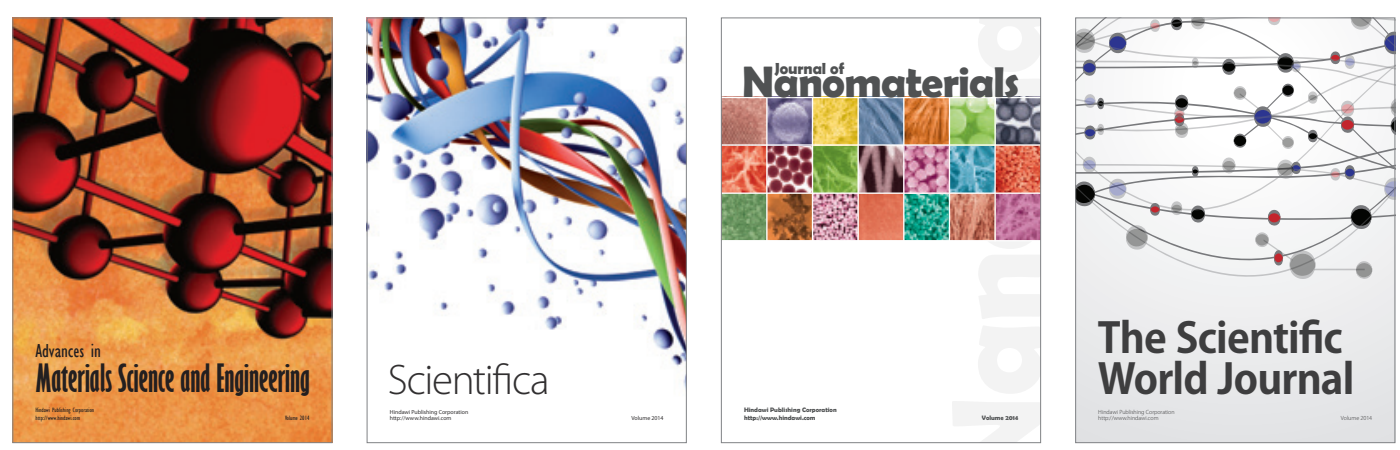

\section{The Scientific World Journal}
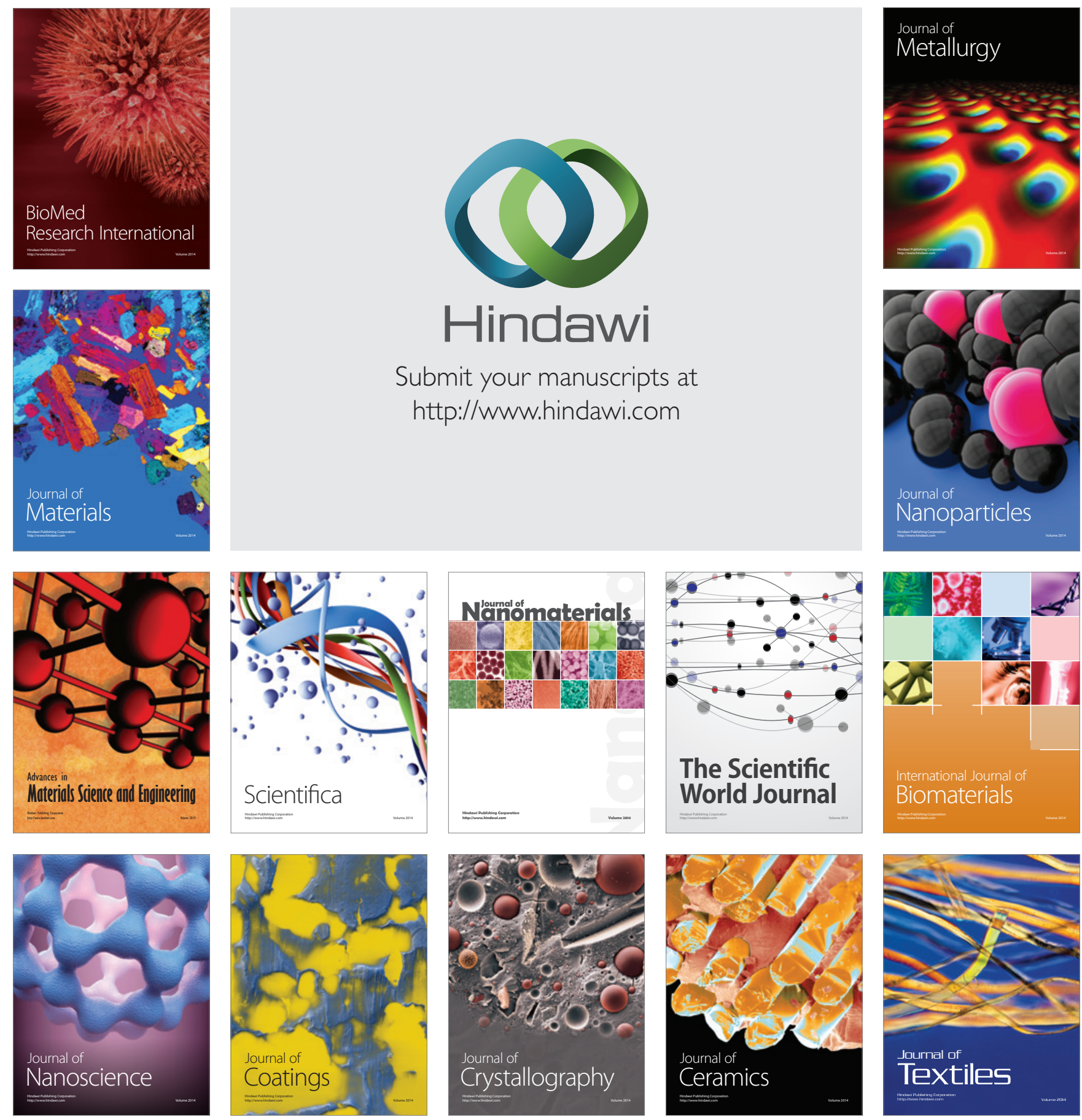